\title{
REGIONAL COST-OF-LIVING ADJUSTMENTS IN TAX-TRANSFER SCHEMES
}

\begin{abstract}
The federal income tax and major welfare programs do not take into account significant cost-of-living variations among regions. This article considers what adjustments might be appropriate in light of the distributive purposes of tax and welfare systems and concerns about the efficiency of the interregional allocation of resources. Price index problems, differences in amenities, and heterogeneity of individuals' locational preferences are considered.
\end{abstract}

Louis Kaplow

Harvard Law School

HFB 322

Harvard University

Cambridge, MA 02138

and NBER 


\section{NBER WORKING PAPER SERIES}

\section{REGIONAL COST-OF-LIVING \\ ADJUSTMENTS IN TAX-TRANSFER \\ SCHEMES}

Louis Kaplow

Working Paper No. 5008
NATIONAL BUREAU OF ECONOMIC RESEARCH 1050 Massachusetts Avenue
Cambridge, MA 02138
February 1995

I am grateful for comments from William Andrews, Reuven Avi-Yonah, Diane Ring, and Steven Shavell. This paper is part of NBER's research program in Public Economics. Any opinions expressed are those of the author and not those of the National Bureau of Economic Research.

(C) 1995 by Louis Kaplow. All rights reserved. Short sections of text, not to exceed two paragraphs, may be quoted without explicit permission provided that full credit, including $\mathbb{C}$ notice, is given to the source. 


\section{Introduction}

The cost of living varies substantially among regions in the United states and within most other large jurisdictions. ${ }^{1}$ For example, it is well known that an income of $\$ 30,000$ does not go nearly as far in New York City or Alaska as it does in most rural areas. It has been estimated that there is a 428 variation in the cost of living among states in the continental United states. ${ }^{2}$ Nonetheless, the federal income tax takes no account of cost-of-living variations, nor do major welfare programs. ${ }^{3}$

By contrast, it is generally accepted that changes in the cost of living over time should be reflected in the tax system, and the rate structure of the federal income tax has been indexed for inflation since 1981.4 Although indexing has long received substantial academic attention, the appropriateness of regional adjustments has been neglected. ${ }^{6}$ There are important similarities between these cost-of-living concerns, but there is

1 The cost of living also differs among countries; the present analysis thus would be relevant if different nations, as in the EC, attempted to harmonize personal tax-transfer policy.

2 See McMahon (1991). Note that relevant regions are often smaller than states, as urban-rural differences in land prices can be large.

3 There are exceptions. Section 912 of the Internal Revenue Code exempts from tax certain cost-of-living allowances paid by the United States to employees stationed outside the continental United States. Food stamp benefits are higher outside the continental United States. Some important welfare programs, notably AFDC, allow states to set benefit levels, which vary greatly among states in a matter that does not closely reflect cost-of-living differences.

4 Social security benefits and the wage ceiling for tax contributions also are indexed.

5 See, e.g., Aaron (1976), Shuldiner (1993).

6 Brief comments appear in Mieszkowski (1979, p. 31). 
also a fundamental difference: regional cost-of-living differences are "real" in a sense that inflation is not. For example, an individual with savings (a retiree) can move to a lower-cost region and thereby achieve a higher standard of living (but he obviously cannot move to an era with lower prices, keeping the amount of nominal dollars intact). Similarly, the government can raise a dollar in taxes in a high-cost region and spend it in a low-cost region without the dollar losing value in the process.

This article undertakes a preliminary conceptual investigation of regional cost-of-living adjustments in the tax system (hereinafter understood to include transfers to the poor).7 It examines what if any adjustments might promote the distributive objectives of the tax system and whether adjustments are efficient. To assess these effects, it is necessary to consider the sources of regional cost-of-living differences, how wage rates respond to such differences, and how the resulting market equilibrium would adjust if taxes were changed, subjects that have been studied previously by labor economists and urban and regional economists. ${ }^{8}$

\footnotetext{
7 The analysis considers only wages, which tend to be earned and spent in the same region. Capital income is not generally earned in the region of residence, and, due to the mobility of capital, rates of return would not adjust to cost and amenity differences as would wages. As a result, the analysis would differ.

8 See, e.g., Rosen (1979, 1986), Roback (1982, 1988), Blomquist, Berger, and Hoehn (1988), Hoehn, Berger, and Blomquist (1987), Henderson $(1982,1987)$. The analysis is similar to some work by public economists who study local public goods and finance in that all emphasize how labor and capital migrate in response to economic conditions. See, e.g., Mieszkowski and Zodrow (1989), Rubinfeld (1987).
} 
Section 2 describes how wages and the cost of living are determined in equilibrium. The discussion is straightforward and brief; it serves as background for the analysis that follows.

Section 3 uses a few simple cases to illustrate the effects of adjusting taxes to reflect cost-of-living differences. When the prices in one region are uniformly higher than in another, a price index adjustment to grants or income tax exemptions and to rate brackets -- analogous to indexing for inflation -- suffices to produce a system in which individuals in different regions with equal utility before taxes and transfers also have equal utility after taxes and transfers. Such a result is consistent with preserving efficient production among regions; in the absence of any adjustment, the tax/transfer system would induce migration to low-cost regions. But such adjustments may not be optimal with regard to the distribution of income. Moreover, a given degree of redistribution can be accomplished more cheaply by departing from such a scheme. In particular, making the tax/transfer scheme in low-cost regions more progressive (higher tax rates, more generous welfare payments) than in high-cost regions induces a pattern of migration that has the effect of reducing the government's cost of transfer payments.

Section 4 extends the analysis in a number of ways. First, it introduces price index problems, which do not fundamentally alter the analysis. Second, it addresses interregional variations in amenities, which greatly complicate any attempt to account for cost-of-living differences and may render any adjustments counterproductive. Finally, it considers 
heterogeneity in individuals' preferences for location-specific amenities. Concluding remarks are offered in section 5 .

\section{Equilibrium Determination of Cost of living and Wages'}

Workers are assumed to decide jointly where to live and where to work. Although residences and jobs can be adjusted independently, there are limits: for the most part, individuals must live and work in the same area. Workers' decisions will maximize their well-being, taking into account wages and working conditions, housing costs and other cost-of-living differences, and amenities (crime, pollution, recreational opportunities) associated with different locations.

Employers and suppliers of capital similarly will choose locations. Employers will consider differences in local costs: wages, rents, and prices of other inputs. Capitalists will be attracted to investments with the greatest returns, wherever located.

The process of adjustment can be illustrated by considering the possibility that workers find the overall combination of attributes in area $A$ more desirable than those in area B. (Wages or amenities may be higher in $A_{;}$cost of living may be greater in B.) Under these circumstances, workers would tend to migrate from $B$ to $A$. As more workers move to $A$, there will be some tendency for prices, particularly land rent, to be bid upward by the increase in demand; similarly, the increase in the supply of

9 For references, see note 8 . 
labor will bid wages downward. (In B, prices will fall and wages will rise as workers leave.) These adjustments will reduce the relative attractiveness of A relative to B. In equilibrium, workers will be indifferent between locating in $A$ or $B .{ }^{10}$

Firms and suppliers of capital make similar adjustments. Thus, if wages are higher in A, firms would tend to locate in B, which will reduce labor demand and thereby wages in $A$ and increase them in B, a process that will continue until firms' costs of producing tradable goods are equalized across regions. (The costs of producing nontradable goods, such as many personal services, need not be equalized in equilibrium. If costs are higher in A, prices will be higher in A, contributing to a greater cost of living in A.) If, due to higher costs of other inputs, the return to capital is lower in $A$, capital will move to B, gradually increasing the return in $A$ and reducing it in $B$, until equilibrium is reached.

Observe that, in equilibrium, it is entirely plausible for cost of living to differ among regions. One important reason is the existence of inherent production cost differences. oil or fish may be cheaply obtained in Alaska; thus, employers will be willing to offer higher wages to induce individuals to reside there despite higher living costs. Another reason, explored in section 4 , is that amenity differences may induce individuals to concentrate in some areas, which may increase the cost of living as land rents are bid upward. Most of the discussion to follow

\footnotetext{
10 When workers are heterogeneous, as explored in section 4, only the marginal worker will be indifferent; some workers in A will strictly prefer A and others in $B$ will prefer $B$.
} 
will consider long-run equilibrium and how it changes depending on the existence and form of regional cost-of-living adjustments.

\section{Basic Analysis of Cost-of-Living Adjustnents}

To simplify the exposition, this section will focus on the case of pure cost-of-living differences -- i.e., the situation in which there are no nonpecuniary differences in amenities. Thus, wages and prices for goods and services are all that individuals will care about. Similarly, firms care only about input prices and the price at which they can sell their goods and services.

Furthermore, the analysis in this section will consider the case in which cost-of-living differences for consumers take a simple, proportional form. Assume that each good in the highcost region ("H") costs $\lambda$ times its cost in the low-cost region ("L"). 11 For example, if $\lambda=1.25$, all goods and services are 25\% more expensive in $H$ than in $L$. (Readers will recognize that this assumption eliminates familiar index number problems; the assumption will be relaxed in section 4.) observe that, in longrun equilibrium, if the wage for a worker of a given ability level in L is $w$ (say, $\$ 10.00$ per hour), the wage for such a worker in $H$ must be $\lambda W(\$ 12.50)$, because that wage provides the same consumption opportunities. (If the wage in $\mathrm{H}$ were higher than $\lambda w(\$ 12.50)$, such workers would migrate to $H ;$ if lower, they would migrate to L.)

11 The discussion in the text ignores that $\lambda$ is endogenous. For example, raising taxes in $\mathrm{H}$ may raise wages, which would result in higher prices, increasing $\lambda$. Because most of the analysis focuses on equilibrium conditions, however, this complication can be ignored. 


\section{A. Benchmark: Adjustment to Equalize Utility Across Regions}

This section asks what adjustment to the tax and transfer system is required so that two individuals, one in $\mathrm{H}$ and the other in $\mathrm{L}$, who would have equal utility in the absence of taxes would also have equal utility after the imposition of taxes. This may appear to be a horizontal equity norm, but I do not posit any normative significance to this benchmark at this point in the analysis. Rather, this benchmark is simple and is a natural starting point: in the case of proportional cost-ofliving differences just described, it involves adjustments analogous to indexing for inflation. Moreover, as section B will discuss, benchmark treatment will have attractive efficiency properties. It may not, however, be best with regard to income distribution, and the appropriate adjustment will change when there are interregional differences in amenities.

This question of what adjustment will maintain equal utility is answered under the static assumption that individuals do not change behavior or locations, wages do not adjust, and so on. observe, however, that if the posited cost-of-living adjustment is made, the tax system will not directly induce migration because the before- and after-tax comparisons for individuals with a given level of skill will be unaffected. As a result, the pre-existing (no tax) interregional equilibrium will be undisturbed. ${ }^{12}$

\footnotetext{
12 For qualifications, see note 15.
} 
To address this question, consider a purely proportional income tax. That is, $T(y)=t_{y}-g$. This is a negative income tax: individuals pay taxes at the rate $t$ on all their income $(y)$ and receive a grant of $\mathrm{g}$. It is equivalent to an income tax with a zero bracket combined with a welfare system that provides a grant to the poor that is phased out at the rate $t$, with phaseout complete at $y=g / t .{ }^{13}$ This is the simplest scheme that includes both an income tax and welfare. Analysis for a scheme with additional brackets is essentially the same; occasional comments or footnotes will offer further remarks where necessary.

If $T(y)$ is the tax scheme for region $L$, then equal utility will result if one applies the scheme $T_{B}(Y)=t_{Y}-\lambda g$ in region H. That is, there is no deduction, no adjustment of the tax rate, and only a change in the grant level. To demonstrate this, observe that, in the absence of taxation, an individual in $\mathrm{H}$ who earns $\lambda y$ has the same utility as one in $L$ who earns $y$. Under the posited tax, the individual in $\mathrm{H}$ has an after-tax income of

$$
\lambda y-(t \lambda y-\lambda g)=\lambda[(1-t) y+g] .
$$

The after-tax income of the individual in $\mathrm{L}$ is

$$
y-\left(t_{y}-g\right)=(1-t) y+g .
$$

The after-tax income of the individual in $H$ is $\lambda$ times that of the individual in $L$, so it will enable the purchase of goods and

\footnotetext{
13 The scheme is also similar to a two-bracket tax, where the first bracket is subject to a zero rate. The amount of exempt income $E$ times the tax rate $t$ would equal $\mathrm{g}$. For individuals who earn more than $\mathrm{E}$, the result is identical. (That the first $E$ of income is exempt saves $g$ dollars.) For those earning less than $E$, the system with an exemption rather than a grant is less generous (unless welfare payments make up the difference).
} 
services of the same value. Moreover, this result holds regardless of the income level ( $y$ ) at which one makes the comparison. (By contrast, if one adjusted the tax rate to preserve equality between regions in the buying power of aftertax income at one income level, the buying power of after-tax income would differ at other income levels. Thus, a lower tax rate in the high-cost region would produce a relatively greater benefit than the grant adjustment for high-income taxpayers and a relatively lower benefit for low-income taxpayers.)

To extend the result to multiple brackets, the income levels at which each bracket begins for taxpayers in $\mathrm{H}$ would be multiplied by the same factor $\lambda$. Observe that this regional cost-of-living adjustment is the same as that done over time when indexing tax rates and grant payments for inflation.

To explore further the intuition behind this conclusion, it is useful to consider more directly the effect of regional costof-living differences on utility. Suppose that $\lambda=1.25$, income (y) for an individual in $\mathrm{L}$ is $\$ 20,000, t=10 \%$, and $g=0$. In a world with no taxes, an individual in $\mathrm{H}$ who earns $\$ 25,000$ would have the same utility as the individual in $\mathrm{L}$. One might argue that it is improper to include the entire $\$ 25,000$ as taxable income, for it only buys as much as $\$ 20,000$ in $L$, the reference region. This is true, so one could allow a deduction of $20 \%$ of income, $\$ 5000$, and apply the 10 tax to $\$ 20,000$ (which equals actual income times $1 / \lambda)$, as is done in region $L$. Individuals in both regions would then owe $\$ 2,000$. Observe, however, that the individual in $H$ suffers less from paying $\$ 2,000$ than the 
individual in $\mathrm{L}$ : in $\mathrm{H}, \$ 2,000$ only buys what $\$ 1,600$ would in $\mathrm{L}$. To make these individuals' tax burdens equal in utility terms, the individual in $H$ would have to pay taxes that are 258 more than $\$ 2,000$, or $\$ 2,500$ (which equals the initial tax assessment times $\lambda$ ). But that is simply the tax burden that would have resulted from applying $t=108$ to income of $\$ 25,000$ without any adjustments. In sum, "ability to pay" is lower on account of the higher cost of living in $H$, but so is the burden of any dollar paid in tax.

In this simple case of a purely proportional tax, these effects precisely offset, so no cost-of-living adjustment is required. In the illustration, there were two adjustments: before-tax income was multiplied by $1 / \lambda$ and the initial assessment of tax due was multiplied by $\lambda$. Obviously, these two adjustments are offsetting. The same logic holds with a progressive system, as shown in the margin. ${ }^{14}$

\section{B. Efficiency}

The equal utility adjustment was offered as a benchmark, not as a normative criterion. This section begins the normative analysis by considering whether such treatment is efficient.

\footnotetext{
14 Consider a two-bracket tax, where income less than $B$ is taxed at the rate $t_{1}$ and income above $B$ is taxed at the rate $t_{2}$. An individual in $L$ who earns $y$ $>B$ pays tax of $t_{1} B+t_{2}(y-B)$. Cost-of-living adjustment involves setting $B_{H}=\lambda B$. Then, one in $H$ who earns $\lambda y$ pays tax of $t_{1} \lambda B+t_{2}(\lambda y-\lambda B)$. As required by the benchmark, observe that tax paid in $\mathrm{H}$ on $\lambda y$ equals $\lambda$ times the tax paid in $L$ on $y$. Thus, one can begin with $\lambda y$; make the cost-of-living adjustment to income by multiplying $1 t$ by $1 / \lambda$, which yields $y$; determine taxes owed in $L$ for that income, which are $t_{1} B+t_{2}(y-B)$; and make the reverse costof-living adjustment to this initial tax assessment by multiplying it by $\lambda$, which yields $t_{1} \lambda B+t_{2}(\lambda y-\lambda B)$ as the tax owed on $\lambda y$ in $H$.
} 
The benchmark adjustment is designed so that individuals with equal utility before taxes and transfers have equal utility after taxes under the static assumption of no adjustments. This tax treatment has the property that, as a first approximation, equilibrium is unaffected. ${ }^{15}$ Individuals who initially were indifferent between regions $H$ and $L$ will continue to be indifferent, so the tax system does not directly induce migration. Moreover, because labor is unaffected, previously existing wages will continue to clear the market. In the absence of uncorrected distortions, the pre-tax equilibrium is efficient. As a result, the allocation of labor between regions -- and thus of production -- continues to be efficient.

By contrast, if there were no cost-of-living adjustment, the real benefit of the grant component of the tax -- or any exemption or lower brackets -- will be less in $H$ than in $L$. This will induce individuals to migrate to $L$, which would cause wages in $H$ to rise and in $L$ to fall. In equilibrium, individuals would necessarily be indifferent between $H$ and $L$, but the allocation of labor and thus of production between the regions would be distorted by the tax system. The benchmark adjustment, therefore, is that which leads to production efficiency. ${ }^{16}$

15 The conclusion is an approximation because imposing a labor income tax will affect work effort. Even if the uncompensated supply elasticity were zero, the grant component of the tax will have an income effect, leading individuals to work less. As labor adjusts, wages in turn may need to adjust. One might expect some migration if the production technology or prices of other Inputs in the regions differ.

16 It is no accident that the benchmark treatment results in no interregional distortion. The interregional equilibrium condition for labor is that utility be equal between jurisdictions. Introducing a tax with cost-of-living adjustments that preserve relative utility levels between regions will not directly alter this equilibrium. 


\section{c. Redistribution between Regions}

Consider now the distributive properties of the posited adjustment. Under most welfarist criteria, the resulting distribution is not optimal. For individuals at any level of utility, the marginal utility of a dollar is less in $H$ than in $L$ because a dollar in $\mathrm{H}$ buys only $1 / \lambda$ as much as a dollar in $L$ would buy. Transferring dollars from those with low marginal utility to those with high marginal utility, as by increasing $t_{B} / t_{I}$ or reducing $g_{B} / g_{I}$ from the benchmark levels (of 1 and $\lambda$ respectively), increases total utility and thus welfare. Although individuals who live in $H$ rather than $L$ and thus have higher income are not rich in the sense of being better off, they have the attribute of richer individuals that their marginal utility of income is lower, and it is this attribute that motivates redistribution from a welfarist perspective. ${ }^{17}$ In sum, redistributing some income from individuals in $H$ to those in $L$, by raising the relative tax rate in $\mathrm{H}$ or lowering the relative grant amount, would raise welfare.

A countervailing consideration is that any adjustment that relatively favored region $L$ would induce migration to $L$ and thus would be inefficient. As a result, if labor is mobile, there is an efficiency cost. But, starting from the benchmark treatment

\footnotetext{
17 A more egalitarian (than utilitarian) welfare function would be concerned about the inequality in utility levels that would result. But, as long as it was not an extreme maximin welfare function, some deviation from the equal treatment benchmark of the sort described in the text would be increase welfare: starting from the point of equal utilities between the regions, a small deviation would initially have a zero marginal cost to social welfare. By contrast, the marginal utility effect is positive for a small redistribution.
} 
which involves no distortion, the marginal efficiency cost of a small adjustment would be zero, whereas the marginal distributive benefit would be positive. Thus, even considering this efficiency cost, some redistribution relative to the benchmark would increase welfare. That is, it would appear that an optimal scheme would tax the high-cost region more heavily, or at least fail to inflate fully the grant amount (or exemptions or tax brackets) to reflect the higher cost of living.

This distributive analysis, however, is incomplete because it neglects general equilibrium adjustments in wages. As labor migrates from $H$ to $L$, wages in $H$ would rise and wages in $L$ would fall. Such wage adjustments have a distributive effect opposite to that of the tax adjustment: individuals in $\mathrm{H}$, who have a lower marginal utility of income, earn more, and individuals in $L$ earn less.

If labor is completely mobile in the long run, no net redistribution would result. To see why this is true, observe that, in equilibrium, individuals must be indifferent between living in $\mathrm{H}$ and $\mathrm{L}$. Thus, individuals of a given ability will have the same after-tax (real) wages and incomes in both regions. This implies that wage adjustments are not only in the opposite direction of tax adjustments but also of the same magnitude, so the offset is complete. (More precisely, the relative pre-tax wage rises in $H$ by a sufficient amount that the after-tax wages in the regions are equal in equilibrium). 
The conclusion, then, is that the hypothesized redistributive adjustment would be ineffective in achieving its redistributive objective and, by inducing migration, would cause some inefficiency in the allocation of production between the two regions. ${ }^{18}$ If labor is immobile (which is plausible to some extent in the short run), however, redistributive benefits are possible.

\section{Redistribution, Location, and Revenue}

The previous discussion suggests that, at least in long-run equilibrium, one cannot improve the distribution of income by making taxes more generous than benchmark treatment in the lowcost region. Consider another possibility: making the tax more redistributive in the low-cost region. Suppose that, relative to the benchmark (in which the same $t$ applies in both regions and the grants are $g$ and $\lambda g$ in $L$ and $H$ respectively), one raised both $t_{l}$ and $g_{l}$ slightly. This change would make living in $L$ more attractive to low-wage workers (including those who do not work): the gain from a higher grant would exceed the cost of having one's income taxed at a higher rate because little income is earned. Conversely, living in L would be less attractive for high-wage workers.

This change would induce low-wage workers to migrate from $\mathrm{H}$ to $\mathrm{L}$ and high-wage workers to migrate from $\mathrm{L}$ to $\mathrm{H}$. Suppose that the increases in $t_{L}$ and $g_{L}$ were calibrated so that the total

\footnotetext{
18 The idea that market adjustments may nullify equity effects leaving only efficiency effects is familiar from the writing of Bittker (1975, 1979), among others.
} 
amount of effective labor in the regions was the same in equilibrium as it was initially. That is, assume that all labor is fungible except for the effective effort per hour supplied. Then, relative wages among individuals in a region would indicate the ratio of their effective labor. One might imagine, for example, that for each individual who would have earned $w$ in $L$ who migrates to $H$, where the wage had been $\lambda w$, two individuals who would have earned $\lambda w / 2$ in $H$ migrate to $L$. Then, in the new equilibrium, there will be the same amount of production in each region as before. Because high-productivity workers are concentrated in $\mathrm{H}$ and low-productivity workers are concentrated in $L$ and total effective labor in each region is the same, it must be that the resulting population in $\mathrm{H}$ is smaller and that in L is larger.

The effect of this adjustment is that the government budget has a surplus relative to the initial situation. Each individual still receives a grant, but the dollar amount of the grant in $L$ is smaller than in $\mathrm{H}$ : it is slightly more than $g$ rather than $\lambda$. Because more individuals now live in $L$, less revenue is needed to fund grants, leaving a surplus of slightly less than $(\lambda-1)$ g times the net population move to $\mathrm{L}$. (The revenue collected by the proportional income tax component is not significantly affected, because the same income continues to be earned in each region. ${ }^{19}$ )

The basic idea is simple. Taking the extreme case, it is more efficient if those who receive welfare live in low-cost

19 The tax rate in $\mathrm{H}$ is unchanged. The rate in $\mathrm{L}$ is slightly higher, but slight in this context means very small, so this additional revenue gain would be trivial. 
rather than high-cost areas, for then they can be maintained at the same standard of living at a lower cost to the government. One can induce such locational choices by raising grants in lowcost regions. This makes poor individuals who migrate better off than before, but they are supported at a lower cost to the government. ${ }^{20}$ The generalized version of the argument is that if the tax system as a whole is relatively more progressive in lowcost regions, more efficient redistribution can be accomplished. The reason is that any progressive system is redistributing income to individuals who earn relatively less; by concentrating those who are relatively less well off in low-cost areas, the same redistributed dollars can go further. ${ }^{21}$

In practice, there are efficiency costs to pursuing a policy that induces relatively low-wage workers to migrate to the lowcost region (and conversely induces high-wage workers to migrate to the high-cost region). Workers of different ability typically differ not only in their effective supply of fungible labor, as assumed above, but also in the types of labor they supply. For example, a doctor who earns the wage of five nurses does not do the same work as a nurse in a fifth the time; rather, there is specialization of functions. Thus, it would be inefficient to

20 For evidence that real (cost-of-living adjusted) welfare benefits induce migration, see Cebula (1979).

21 To illustrate the more general case, recall from note 13 that the posited proportional income tax with a grant is equivalent to a two-bracket tax, where the first bracket has a zero rate, the level of exempt income equals $g / t$, and all individuals earn more than the exempt level. The demonstration in the text did not require that any individuals did not work or earned less than any particular amount, such as $\mathrm{g} / \mathrm{t}$. Rather, inducing migration in a manner that keeps total effective labor in each region unchanged has the result of concentrating more individuals, but not more potential tax revenue, in the low-cost, low-wage region. 
induce all nurses to migrate to a low-cost region and all doctors to a high-cost region. Indeed, if one made the tax system slightly more progressive in the low-cost region, this would not happen. Rather, only modest migration would be induced. ${ }^{22}$ The greater the difference in the progressivity of the tax systems, the more labor would move, and the greater the resulting inefficiency in the allocation of labor would be. Thus, there is a trade-off between saving revenue through inducing migration and avoiding inefficiency in the allocation of labor.

Despite this trade-off, some induced migration would be welfare-maximizing. ${ }^{23}$ This suggests that, from a national perspective, efficient redistribution entails low-cost states (Mississippi) having more redistributive tax/transfer systems than high-cost states (New York). Independent decisions by states appear to produce an opposite pattern, perhaps because high-cost states also tend to be high-income states.

22 As migration occurred, wages in $\mathrm{H}$ for low-skill jobs would rise and those in $\mathrm{L}$ would fall, and conversely for high-skill jobs. This would tend to offset the more progressive tax in L. But all individuals who are not working and who have no prospect of working but who receive welfare would be induced to move. Compare the phenomenon of significant numbers of retired individuals migrating - - not only to areas with good climates or other amenities, but also to low-cost regions (where the correspondingly low wages are irrelevant in determining their income).

23 Starting from the benchmark treatment that does not induce migration, a small initial amount of migration would have a zero marginal efficiency cost; the efficiency cost would rise with the amount of migration induced. But the marginal revenue benefit from inducing a small amount of migration is $(\lambda-1) g$ per person of net migration to $\mathrm{L}$, which is not trivial. 
4. Extensions

\section{A. Nonuniform price differences.}

The price index problem. The analysis to this point considers the case in which all prices in $H$ are higher than those in $L$ by the same factor. More realistically, there will be relative price differences. For example, most goods may be sold on national markets and thus have similar prices in each region. In contrast, land scarcity varies substantially, so housing costs may differ greatly. (And, when land prices differ, prices of locally produced nontradable goods, such as personal services, will differ.) Differences in climate may result in different costs for fuel and clothing. Better access to energy or transportation may also affect some costs. Indeed, the "highcost region" may have higher costs for some goods and lower costs for others.

This raises the familiar price index problem. When price ratios differ, individuals will buy different mixes of goods and services. The most important example in the present context probably involves housing. If housing is much more expensive in region $H$, individuals will purchase less. (For example, even rather wealthy individuals who reside in New York City often live in homes of modest size, whereas moderate-income individuals in rural areas may live in larger homes.)

This complication has little effect on the previous discussion. If individuals who might locate in $\mathrm{H}$ or $\mathrm{L}$ have the same preferences, there exists in principle a price index that 
translates income in one region into equivalent income in another. (On heterogeneous preferences, see section 4.) This index simply indicates the relative levels of income that would make individuals indifferent between living in the two regions. One can simply denote this index as $\lambda$, and the above analysis is unaffected.

When the price index is a function of income. When price ratios are different in various regions, it is possible that the price index $\lambda$ would depend on income. For example, if the primary cost difference involves housing and the rich spend a lower portion of their budget on housing, the relevant $\lambda$ would be falling with income. Although this would complicate the details of the argument, the basic points would remain the same. Because the analysis is somewhat involved, it is left to the appendix.

\section{B. Interregional Differences in Amenities}

When regions differ in amenities, cost-of-living comparisons become difficult and cost-of-living adjustments that otherwise seem plausible can become problematic or even counterproductive. Assume, for example, that region A has better amenities than B; perhaps it has better climate or access to recreational opportunities. ${ }^{24}$ If there were no other differences, individuals would prefer to reside in $A$. The result is greater demand for land in $A$, which would tend to bid up land prices. In

\footnotetext{
24 An important category of differences that has been studied by public finance economists involves state and local taxation and provision of services. For discussions of how these issues are related to interregional cost-of-iiving differences, see David (1975), Gillingham and Greenlees (1987), Gyourko and Tracy (1989, 1991), Mieszkowski (1979), Montmarquette (1983).
} 
equilibrium, A will have a higher cost of living than B, if cost of living is measured as the cost of purchasing a given market basket of goods and services, one of which is housing of a given size and quality. Indeed, the single largest source of interregional cost-of-living differences is housing prices, due to the large variations and the fact that housing is a significant fraction of most individuals' expenditures. ${ }^{25}$

In assessing economic well-being, there is no systematic difference between these two regions. Although the price of housing is greater in $A$, housing expenditures entail the purchase of greater benefits: one buys the house itself and access to amenities. ${ }^{26}$ There is no basis for assuming that individuals of a given ability and income are worse off if they live in $A$. (If they were, they would live in B.) In this simple story, in which the value of amenities is fully reflected in land prices and residents get what they pay for, wages in $A$ and $B$ would not differ in equilibrium. ${ }^{27}$ Given all this, achieving the benchmark that individuals in $A$ and $B$ having equal utility without taxes have equal utility with taxes does not require any cost-of-living adjustment. Suppose, however, that one naively makes an adjustment of the sort discussed in section 3, using the price index that reflects greater housing costs in $A$. Such a cost-of-

25 See Buckley (1979), McMahon (1991), Roback (1988).

26 Price index complications of the sort discussed in section 4.A are applicable. Amenities directly affect the price of housing but not other goods and services, so price ratios will differ among regions. Moreover, because the fraction of income spend on housing depends on income levels, the appropriate price index depends on income.

27 This assumes that amenities are not productive. 
living adjustment would move the system from neutral treatment to distorted treatment. ${ }^{28}$

Variations in amenity levels pose a significant problem if any sort of regional cost-of-living adjustments are desired. When amenity levels cannot confidently be measured, one is unsure whether adjustments move the system closer to or further from benchmark treatment (or any other target). As the preceding discussion suggests, the difficulty is not merely hypothetical. There is reason to believe and empirical evidence to support the proposition that land prices reflect amenities. As a result, one would predict that apparent cost-of-living differences are systematically correlated with differences in amenities. Indeed, one study suggests that using regional cost-of-living adjustments would on average reflect differences in well-being less accurately than unadjusted comparisons of wage levels. ${ }^{29}$

A possible empirical approach to determining the existence of real cost-of-living differences that affect well-being is to compare wage levels between regions for particular job types. As explained in section 2, individuals' locational decisions will reflect differences in income-earning opportunities, costs, and amenities. In equilibrium, if wages are higher in region $A$ than in $B$, it must be that cost-of-living differences exceed amenity

28 such an adjustment would make $A$ more attractive, inducing more individuals to move to $A$. In equilibrium, there would by definition be equal utility across regions, but there would be an inefficient allocation of individuals and production among regions.

29 See Roback (1988). Other work on amenity differences includes Roback (1982), Rosen (1979), Blomquist, Berger, and Hoehn (1988), Hoehn, Berger, and Blomquist (1987), Henderson (1982, 1987). 
differences by the amount of the income difference. (If there were no such real cost-of-living differences, labor would migrate to A.) This suggests the possibility of using wage differences rather than price index differences to make regional cost-ofliving adjustments. ${ }^{30}$

There are, however, some problems with relying on wage differences. ${ }^{31}$ First, empirical evidence indicates that interregional wage differences vary by occupation, suggesting that different types of workers have different preferences regarding amenities. ${ }^{32}$ (Preference heterogeneity is considered further in section C.)

Second, temporary labor market disequilibrium would provide misleading indications. For example, suppose that regions $A$ and B were initially identical in wages, nominal living costs, and amenities. Then the demand for products produced in A rises. In the short run, wages will rise in $A$. It would be wrong to infer

\footnotetext{
30 Analogously, one could use wages differences within regions to adjust for nonpecuniary differences in jobs .. an important source of un taxed imputed income. The problem is that within regions, comparisons necessarily involve different occupations, raising problems of determining comparable worth. (E.g., how does one compare a coal miner and a landscaper?) Between regions, one can compare essentially identical occupations; moreover, were it not for the differences in preferences discussed in the text, one could use wage differences for comparable occupations to determine the relevant adjustment for occupations in which no such interregional comparison is possible.
}

31 Some theoretical models and empirical evidence suggests that amenities may be reflected in wages as well as housing prices. For example, instead of an amenity benefit worth 108 of income being reflected in a price index that is 108 higher, with no wage difference, perhaps the price index is only 58 higher and the wage is 58 lower. In this instance, the real cost of living is lower in A. (For prices 58 higher one can buy 108 more). An adjustment based on the negative wage difference would be required for benchmark treatment, analogous to that which would be made if the wage difference were positive. Individuals in $A$ who earn 58 less than those in $B$ are as well off. If one applied an unadjusted income tax, those in A would pay less, leaving them better off after tax.

32 See Buckley (1979), Rosen (1979). 
that individuals in A must therefore suffer from a higher real cost of living (either a higher price index or lower amenities). Rather, those fortunate enough to have been living in $A$ are better off by the amount of the higher wages, so no cost-ofliving adjustment is required to provide benchmark equal utility treatment. Over time, however, labor will migrate to $A$ if region A had real advantages in producing the products for which demand had increased. (If not, production would also expand in B.) In addition to reducing the relative wage differences, one would expect relative land prices in $A$ to rise. In long-run equilibrium, higher wages in A would reflect higher living costs. The extent to which significant real out-of-equilibrium differences persist for substantial periods of time is uncertain. ${ }^{33}$

\section{Variations in Individuals' Locational Preferences}

Individuals consider more than wage levels, price indexes, and general levels of amenities in deciding where to live. First, individuals' preferences among nonpecuniary job attributes, goods and services, and amenities will differ. Second, as a result of personal history, individuals will have

33 One might suspect that they would not. If even a small fraction of individuals relocate each year - - particularly among those graduating from college, getting married, or changing occupations -- the cumulative effect over time will be substantial. Moreover, it is unlikely that there are frequent, large interregional shifts. (Most contemporary changes are not as dramatic as the gold rush or even the decision to build the Alaska pipeline.) On the other hand, empirical studies do find interregional differences in well-being, although the ability to measure amenities is problematic. Observe that the mere existence of continued migration - - say from the Northeast to the South and West - - does not indicate disequilibrium. If there is a predicted long-term gradual change in the relative desirability of regions, one might expect a steady flow of migration with equilibrium prevailing throughout the time period. 
particular locational preferences. Any move may involve significant direct costs. In addition, one develops networks of friends, relationships with institutions, and knowledge of the opportunities an area has to offer. Moving to a different region thus may involve considerable sacrifice. Finally, individuals locational decisions are interrelated: spouses need to make joint decisions, and choices may depend on the location of other relatives.

As a result of the heterogeneity of preferences, it will not be the case that, in equilibrium, most individuals will be indifferent about where they live. Some will be approximately indifferent. They are the ones who would move in response to small changes in wages or taxes or living costs. Many will be inframarginal. If after-tax wages in their region fall, they will be worse off; some of their surplus (the excess of the value they place on their current location over the cost of alternatives) will be eroded. If circumstances become more favorable, they will gain. It would be difficult for the tax system to take into account such differences in consumer surplus, just as it does not attempt to do so in other contexts.

Applying this point to the analysis of section $B$, the equilibrium wage difference between regions will reflect a combination of cost-of-living differences and the amenity preferences of the marginal worker. Such wage differences will tend to understate the amenity benefits of those who are inframarginal, although it may overstate the benefits of some who choose not to move due to the one-time costs of moving. 
The existence of preference variations also implies that the equilibrium adjustment process may be slower than otherwise. Moreover, small wage adjustments or tax differences will induce modest rather than substantial migration. One implication is that if taxes were made relatively higher (or grants relatively lower) in high-cost regions to further distributional objectives (as described in section 3.c), the resulting relative wage increase in the high-cost region may not fully nullify the redistributive effect. Thus, some such redistributive adjustment may be enhance welfare. On the other hand, there will be an additional cost to induced migration: in addition to distorting production, individuals will be induced to live in regions that match their preferences less well.

\section{Conclusion}

Cost-of-living differences among regions are generally ignored in tax and transfer systems even though they are reflected by the market. The present analysis suggests that in principle some adjustments may be appropriate. To explore the issue, a benchmark that preserves equal utility between regions was offered. In the simple case of a purely proportional income tax combined with a uniform grant, benchmark treatment is achieved by adjusting the level of the grant for cost-of-living differences. For an income tax with multiple brackets, the income levels at which brackets begin would similarly be adjusted. These adjustments are like those made when indexing the system for changes over time in the cost of living -inflation. 
Such treatment was found to be efficient, in the sense that imposing taxes and transfers would not distort the interregional allocation of labor and production. The analysis suggested that if labor was immobile, less generous adjustments might enhance welfare, but with mobile labor the equilibrium process would nullify any distributive effects and result in inefficiency. It was also suggested that making the tax/transfer system relatively more progressive in low-cost areas would induce migration of lowincome workers to low-cost areas (and conversely for high-income workers), thereby saving revenue.

To implement a system of adjustments would require information on real cost-of-living differences. The government currently provides extremely limited information and what is available is of low quality. ${ }^{34}$ Moreover, due to interregional differences in amenities that often offset nominal cost-of-living differences, making adjustments using standard price indexes may be counterproductive. The most promising approach would compare wages across regions for identical occupations, although existing evidence does not provide a basis for optimism about using this technique. ${ }^{35}$

34 For discussion of Bureau of Labor Statistics information, see McMahon (1991), Final Report (1982) (reporting on the final release of urban family budget data; funding was discontinued).

35 Nonetheless, industries that employ workers nationwide or worldwide as well as national governments sometimes pay wages designed to reflect cost-ofliving differences. 


\section{References}

Aaron, Henry J., ed. Inflation and the Income Tax. Washington: Brookings Institution, 1976.

Bittker, Boris I. "Tax Shelters and Tax Capitalization or Does the Early Bird Get a Free Lunch?" National Tax Journal 28 (1975): 416-19.

Bittker, Boris I. "Equity, Efficiency, and Income Tax Theory: Do Misallocations Drive Out Inequities?" San Diego Law Review 16 (1979): 735-48.

Blomquist, Glenn C., Mark C. Berger, and John P. Hoehn. "New Estimates of Quality of Life in Urban Areas." American Economic Review 78 (1988): 89-107.

Buckley, John E. "Do Area Wages Reflect Area Living Costs?" Monthly Labor Review 102 (1979): 24-29.

Cebula, Richard J. "Living Costs, the Tiebout Hypothesis, and Welfare Policy." Public Choice 34 (1979): 129-30.

David, Martin. "Measurement of the Cost of Living Including the Public sector." Annals of Economic and Social Measurement 4 (1975): 133-52.

"Final Report on Family Budgets: Cost Increases Slowed, Autumn 1981." Monthly Labor Review 105 (1982): 44-46.

Gillingham, Robert and John S. Greenlees. "The Impact of Direct Taxes on the Cost of Living." Journal of Political Economy 95 $(1987): 775-96$.

Gyourko, Joseph and Joseph Tracy. "The Importance of Local Fiscal Conditions in Analyzing Local Labor Markets." Journal of Political Economy 97 (1989): 1208-31.

Gyourko, Joseph and Joseph Tracy. "The Structure of Local Public Finance and the Quality of Life." Journal of Political Economy $99(1991): 774-806$.

Henderson, J. Vernon. "Evaluating Consumer Amenities and Interregional Welfare Differences." Journal of Urban Economics $11(1982)$ : 32-59.

Henderson, J. Vernon. "General Equilibrium Modeling of Systems of cities." In Handbook of Regional and Urban Economics, vol. II, edited by E. Mills. Amsterdam: North-Holland, 1987. 
Hoehn, John P., Mark C. Berger and Glenn C. Blomquist. "A Hedonic Model of Interregional Wages, Rents, and Amenity Values." Journal of Regional Science 27 (1987): 605-20.

McMahon, Walter W. "Geographical Cost of Living Differences: An Update." AREUEA Journal 19 (1991): 426-50

Mieszkowski, Peter. "Recent Trends in Urban and Regional Development." In Current Issues in Urban Economics, edited by P. Mieszkowski and M. Straszheim. Baltimore: Johns Hopkins, 1979.

Mieszkowski, Peter and George R. Zodrow. "Taxation and the Tiebout Model: The Differential Effects of Head Taxes, Taxes on Land Rents, and Property Taxes." Journal of Economic Literature 29 (1989): 1098-146.

Montmarquette, claude. "Public Goods and Price Indexes." In Price Level Measurement, edited by $w$. Diewart and $c$. Montmarquette. Ottawa: Statistics Canada, 1983.

Roback, Jennifer. "Wages, Rents, and the Quality of Life." Journal of Political Economy 90 (1982): 1257-78.

Roback, Jennifer. "Wages, Rents, and Amenities: Differences Among Workers and Regions." Economic Inquiry 26 (1988): 23-41.

Rosen, Sherwin. "Wage-Based Indexes of Urban Quality of Life." In Current Issues in Urban Economics, edited by P. Mieszkowski and M. Straszheim. Baltimore: Johns Hopkins, 1979.

Rosen, Sherwin. "The Theory of Equalizing Differences." In Handbook of Labor Economics, vol. 1, edited by 0 . Ashenfelter and R. Layard. Amsterdam: North-Holland, 1986.

Rubinfeld, Daniel L. "The Economics of the Local Public sector." In Handbook of Public Economics, vol. 2, edited by A. Auerbach and M. Feldstein. Amsterdam: North-Holland, 1987.

Shuldiner, Reed. "Indexing the Tax Code." Tax Law Review 48 (1993): 537-659. 
Appendix: Price Index a Function of Income

To explore the situation in which the price index is a function of income, consider the case in which there is an additional fixed cost $C$ of living in $H$ rather than $L$ that is independent of income. In an income tax with multiple brackets, the benchmark adjustment would involve raising the income level at which each bracket begins by $c$. (If there was no zero bracket at the bottom, the previous bottom bracket would begin at $c$ and income less than $c$ would not be taxed.) observe that, in this special case, the bracket adjustment is equivalent to granting a deduction of $c$. When the adjustment is made, moreover, two individuals, one each in $\mathrm{H}$ and $\mathrm{L}$, who had equal utility before tax would not only have equal utility after tax, they also would have equal marginal utility.

Consider now the relationship of wages between $H$ and $L$. Equilibrium might seem to require that, for a given ability level, employers in $H$ must pay wages that are higher by $c$. But employers will do this by paying a higher wage rate rather than a lump sum of $c$. (One way to see this is that, for a given ability level, two workers working half time have the productivity of one working full time, so an employer would be unwilling to pay 2c to hire the first pair of workers rather than $c$ when hiring the second individual.) Thus, if $C$ is $\$ 2000$, and a given type of worker in L works 2000 hours at $\$ 10$ per hour, for an income of $\$ 20,000$, one might suppose that the same type in $H$ would have to be paid $\$ 11$ per hour for an income of $\$ 22,000$. But such an 
individual would choose to work more than 2000 hours at that higher wage. ${ }^{36}$ Moreover, he will be better off as a result. (He had the option to be as well off by working 2000 hours, and he will strictly prefer to work more.) Thus, in equilibrium it must be that the wage rises less than $\$ 1$ per hour. Nonetheless, it is unambiguous that those of a given ability who reside in $\mathrm{H}$ will work more and will earn more than peers in $L$ by an amount that exceeds $c^{37}$

This analysis of wages may appear to be mere detail. The bottom line is that individuals in $\mathrm{H}$ earn more, have higher costs, and get some tax relief. But it is no longer true that imposing a tax with the benchmark cost-of-living adjustment leaves individuals of the same type equally well off (before further migration and wage adjustments). The reason is that individuals in $\mathrm{H}$ derive a relatively greater share of their utility from goods and services, purchased by taxable income, rather than leisure. For example, if the tax rate is $10 \%$ and workers in $\mathrm{H}$ earn $\$ 23,000$ in the no-tax equilibrium, their deduction of $\$ 2000$ (or creation of a zero-bracket ending at $\$ 2000$ ) leaves them with tax liability of $\$ 2,100$, whereas those in L pay only $\$ 2,000$. The after-tax difference in income between the regions is $\$ 2,900$, whereas it was $\$ 3,000$ initially, which seems relatively unfavorable to those in $H$. On the other hand,

36 There is a positive substitution effect and no income effect. Because of the added cost $C$, at 2000 hours the marginal utility of income is the same in $\mathrm{H}$ as it was in $\mathrm{L}$. Working another hour earns $\$ 11$ rather than $\$ 10$, which buys an extra dollar of goods and thus induces individuals to give up more of their leisure.

37 If their earnings were higher by $C$ or less, they would be less well off, for their income buys a lower standard of living and they enjoy less leisure. This cannot be an equilibrium. 
because the level of after-tax income in both regions is lower than before-tax income, the marginal utility of income in both regions is higher after payment of taxes. A difference of $\$ 2,900$ after taxes could thus have a utility effect that is more or less than that resulting from the difference of $\$ 3,000$ before taxes, depending on the rate at which marginal utility rises as income falls. Unless these two effects are precisely offsetting, imposing the income tax with the posited cost-of-living adjustment will induce some migration.

More generally, whenever the price index varies with income, the sort of complication described here will arise. The formula for benchmark (equal utility) treatment becomes rather complex even for a simple, purely proportional tax with a grant. In this case,

$$
g_{H}=\lambda_{a} g_{L}+(1-t) y_{H}\left[\frac{\lambda^{-\lambda} b}{\lambda_{b}}\right]
$$

where $\lambda_{b}$ and $\lambda_{a}$ refer respectively to the price index applicable to the before- and after-tax income levels. For individuals whose net tax payment is positive, the grant in $\mathrm{H}$ exceeds that given by applying the after-tax cost-of-living index to the base grant level (the term in brackets is positive when the price index falls with income). Because the tax decreases disposable income, the cost-of-living effect becomes relatively larger, so a further grant adjustment is required to offset this effect to make after-tax utilities equal between the regions. In the extreme example of a fixed difference, the grant adjustment is to add tc, which is equivalent to allowing a deduction of $c$ or adding a zero bracket for the first $C$ of income. (As income 
becomes high, the cost-of-living index approaches one, but the amount of this grant adjustment does not fall.)

Finally, consider which types of workers will reside in $H$ and L. Beginning in a world without taxes, there will be a tendency for high-ability types to reside in $H$ and low-ability types to reside in $L$. The reason is that the cost-of-living difference involves a fixed cost. Therefore, less of a relative wage increase is required for high-ability types to be willing to live and work in $\mathrm{H}$. (In the extreme case in which labor is fungible except for effective effort per hour of work, there would be perfect sorting.)

This incentive for sorting will remain in the presence of an income tax that includes the benchmark adjustment. Revenue would be increased, as in the case of cost-of-living differences that did not depend on income, by making the tax/transfer scheme in $\mathrm{L}$ more attractive to low-income workers and less attractive to high-income workers. After all, permitting a deduction or exemption of $\mathrm{C}$ to individuals in $\mathrm{H}$ is equivalent to raising the grant in $\mathrm{H}$ by $t C$. Thus, the smaller the population in $\mathrm{H}$, the lower is the revenue cost of this adjustment. In this instance, the market will already have induced some sorting. Deviating from the benchmark adjustment to induce further sorting would raise revenue. ${ }^{38}$

38 As before, beginning from a tax regime that did not affect the no-tax allocation of workers among regions, there would be a trivial (approximately zero) efficiency cost from making an initial adjustment, implying that the optimum would involve some adjustment. Compare note 23 . 
In summary, the possibility that the price index is a function of income, which arises when there are nonuniform price differences, adds complexity to the analysis but does not fundamentally alter the basic approach. In principle, one can determine benchmark cost-of-living adjustments that produce equal utility in a static world (i.e., without migration and wage adjustments). Such treatment is consistent with an efficient allocation of labor and production among regions. But some deviation designed to sort individuals, with low-wage types concentrating in low-cost areas, would tend to be welfaremaximizing because of the revenue savings involved. 